\title{
The case for removing intellectual disability and autism from the Mental Health Act - ERRATUM
}

Sheila Hollins, Keri-Michèle Lodge and Paul Lomax

https://doi.org/10.1192/bjp.2019.26 Published online by Cambridge University Press, 24 April 2019

In the original published version of the above article, an error was made in the spelling of the name of the first author, Sheila Hollins. The online version of the article has now been corrected. The publisher apologises for the error.

Keywords: Intellectual disability; psychiatry and law; human rights.
Sheila Hollins; Keri-Michèle Lodge; Paul Lomax

\section{Reference}

Hollins S, Lodge KM, and Lomax P. The case for removing intellectual disability and autism from the Mental Health Act. Br J Psychiatry 2019. https://doi.org/10.1192/ bjp.2019.26 